\title{
The relationship between sensory reactivity differences and mental health symptoms in preschool-age autistic children
}

Article

Published Version

Creative Commons: Attribution 4.0 (CC-BY)

Open Access

Rossow, T., MacLennan, K. and Tavassoli, T. (2021) The relationship between sensory reactivity differences and mental health symptoms in preschool-age autistic children. Autism Research. ISSN 1939-3806 doi: https://doi.org/10.1002/aur.2525 Available at https://centaur.reading.ac.uk/97714/

It is advisable to refer to the publisher's version if you intend to cite from the work. See Guidance on citing.

To link to this article DOI: http://dx.doi.org/10.1002/aur.2525

Publisher: John Wiley

All outputs in CentAUR are protected by Intellectual Property Rights law, including copyright law. Copyright and IPR is retained by the creators or other copyright holders. Terms and conditions for use of this material are defined in the End User Agreement. 


\section{CentAUR}

Central Archive at the University of Reading

Reading's research outputs online 


\title{
The relationship between sensory reactivity differences and mental health symptoms in preschool-age autistic children
}

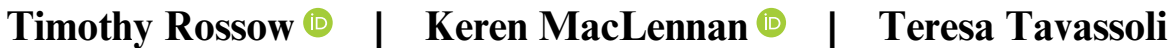

School of Psychology and Clinical Language Sciences, University of Reading, Reading, UK

Correspondence

Harry Pitt Building, Earley Gate, University of Reading, Reading RG6 6BZ, UK

Email: t.w.1.rossow@pgr.reading.ac.uk

Funding information

Autistica; MQ; MQ: Transforming Mental

Health; University of Reading

\begin{abstract}
There is growing evidence for an association between sensory reactivity and mental health in autism. This study set out to explore the relationship between sensory reactivity and mental health in preschool-aged autistic children. In total 54 preschool-aged children with an Autism Spectrum Condition took part. Sensory and mental health symptoms were obtained from the Sensory Processing Scale Inventory, Sensory Assessment of Neurodevelopmental Differences and the Behavioral Assessment System for Children-3. Correlational analyses showed a relationship between sensory reactivity and mental health symptoms in autistic preschool-aged children. Results also indicate divergence in sensory-mental health profiles between autistic preschool-aged children who are verbal and those who use few to no words. For the first time this study has revealed a relationship between sensory hyper-reactivity, as well as sensory seeking, and mental health symptoms outside of anxiety in autism. Of note, this relationship between sensory hyper-reactivity and internalizing symptoms appears to be driven by those with few to no words. This has implications for both research and clinical interventions, in particular for our understanding of the factors underlying mental health symptoms in different autistic phenotypes, as well as the possible role of functional communication in mitigating the development of mental health symptoms.
\end{abstract}

Lay Summary: The present study found that in autistic preschoolers, externalizing mental health symptoms, such as hyperactivity, are related to sensory seeking (seeking out or being fascinated with sensory stimuli), and internalizing mental health symptoms, such as depression, are related to sensory hyper-reactivity (sensitivity to sensory stimuli). Our results also show that whilst the relationships between externalizing symptoms and sensory seeking is seen across participants, the relationship between internalizing symptoms and sensory hyper-reactivity was only seen in autistic preschoolers who used few to no words. This has important implications for the assessment of sensory differences as part of more rigorous mental health assessments, especially in autistic people who use few to no words.

\section{K E Y W O R D S}

autism, children, mental health, psychopathology, sensory reactivity

\section{INTRODUCTION}

Sensory reactivity, such as hyper-reactivity (sensitivity to sensory stimuli, such as being overwhelmed by sounds), hypo-reactivity (under-responsiveness to sensory stimuli, such as not noticing when touched), and sensory seeking (seeking out or being fascinated with sensory stimuli, such as spinning objects), are common in autistic ${ }^{1}$

This is an open access article under the terms of the Creative Commons Attribution License, which permits use, distribution and reproduction in any medium, provided the original work is properly cited.

(C) 2021 The Authors. Autism Research published by International Society for Autism Research and Wiley Periodicals LLC. 
individuals (Leekam et al., 2007; Marco et al., 2011; Tavassoli et al., 2018; Tomchek \& Dunn, 2007). Rates of sensory reactivity have been reported as high as $95 \%$ in autistic populations (Tomchek \& Dunn, 2007), with sensory reactivity showing to significantly impact many areas of functioning, including communication (Lane et al., 2010; Miller et al., 2007; Watson et al., 2011; Zachor \& Ben-Itzchak, 2014), socializing (Glod et al., 2015; Hilton et al., 2007; Hilton et al., 2010; Thye et al., 2018), eating (Cermak et al., 2010; Paterson \& Peck, 2011; Zobel-Lachiusa et al., 2015), sleeping (Hollway et al., 2013; Mazurek \& Petroski, 2015; Reynolds et al., 2012), toileting (Beaudry-Bellefeuille \& Lane, 2017; Cupelli et al., 2014), and oral care (Bartolomé-Villar et al., 2016; Stein et al., 2011, 2013). Whilst autistic individuals, including children, tend to show greater differences, these associations between occupational and behavioral functioning and sensory reactivity appear to be omnipresent, including in populations outside of autism (Bar-Shalita et al., 2008; Boterberg \& Warreyn, 2016; Carr et al., 2010; Dean et al., 2018; Sinclair et al., 2019).

There is also growing evidence for the association between sensory reactivity and mental health. Extant literature has so far implicated sensory reactivity differences primarily in anxiety conditions (Glod et al., 2015; Goldsmith et al., 2006; Green \& Ben-Sasson, 2010; Liss et al., 2005; MacLennan et al., 2020) and schizophrenia (Brown et al., 2002; Javitt, 2009; Javitt \& Freedman, 2015; Yeap et al., 2008). However, there is evidence to suggest that sensory reactivity plays a role in other conditions, including depression, bipolar disorder, obsessive compulsive disorder (OCD), and attention deficit hyperactivity disorder (ADHD) (Bailliard \& Whigham, 2017; Engel-Yeger et al., 2016; Serafini et al., 2017). Moreover, at a mental health symptom level, sensory reactivity has broadly been associated with inattention, withdrawal, hyperactivity, aggression, emotional dysregulation, fearfulness, irritability, impulsivity, and alexithymia (Dean et al., 2018; Engel-Yeger et al., 2016; Liss et al., 2008; Serafini et al., 2017; Tseng et al., 2011). Gouze et al. (2009) assert that differences in sensory reactivity in preschool-aged neurotypical children is a risk factor in the development of mental health symptoms, with evidence emanating from studies of both behavior (i.e., questionnaire) and physiology (Gouze et al., 2009).

Studies in autism have further highlighted that autistic people, as well as presenting with higher levels of sensory reactivity, are also at a significantly higher risk of developing a comorbid mental health condition than their non-autistic peers (Kreiser \& White, 2015; Russell et al., 2016). A large proportion of autistic children experience their first mental health symptoms prior to the age of five (Carter et al., 2003; Green et al., 2012). Whilst the American Psychiatric Association (American Psychiatric Association, 2013) report prevalence rates of comorbid mental health disorders in autistic children of up to $70 \%$, and $40 \%$ with multiple comorbidities, many clinical, selfand parent-report studies have reported rates above this, and as high as 95\% (Caamaño et al., 2013; Gjevik et al., 2011; Lugnegård et al., 2011; Lundström et al., 2015; Margari et al., 2019; Simonoff et al., 2008). A recent systematic review and meta-analysis provides estimated autism population prevalence for diagnostic clusters and disorders, including for ADHD (28\%), anxiety disorders $(20 \%)$, depressive disorders $(11 \%)$, and disruptive, impulse control and conduct disorders (12\%) (Lai et al., 2019). Further, a review of the National Institute of Mental Health's (NIMH) Research Domain Criteria (RDoC) framework has highlighted the lack of research into sensory reactivity and mental health, and identified the need for further investigation across mental health symptoms and diagnoses in autistic individuals (Harrison et al., 2019). It is noted, however, that there remains conjecture around the accuracy of prevalence rates reported in the literature stemming from the heterogeneity of measures used to assess mental health (Lai et al., 2019; Stadnick et al., 2017), and speaks to the broader issue within autism research of measures, particularly those for children, not being validated in an autistic population. Given the variety of presentations inherent in a spectrum condition, any investigation of autism phenotypes, including for sensory reactivity and mental health symptomology in autism, should also endeavor to incorporate the experiences of individuals across the spectrum. Currently, the majority of the literature in the field of autism has neglected to include autistic people who are minimally or non-verbal (Jack \& Pelphrey, 2017; Stedman et al., 2019), henceforth defined as 'few to no words' in line with the Module 1 classification algorithm in the Autism Diagnostic Observation Schedule (ADOS-2) (Lord et al., 2012) and endorsed by autism research charities, such as Autistica. Whilst approximately $30 \%$ of preverbal autistic individuals develop minimal or no verbal language, comparatively few autism studies, including mental health studies, have investigated or included as part of their methodology participants who use few to no words (Tager-Flusberg \& Kasari, 2013). Mental health studies which have included this population show a pattern of reduced symptom severity in school-aged (5-18 years) autistic participants who use few to no words. In particular, verbal autistic children show higher severity scores for depression, somatic complaints, oppositional defiance disorder, generalized anxiety disorder and overall internalizing problems when compared with their peers who use few to no words (Fok \& Bal, 2019; Lerner et al., 2018; Skwerer et al., 2019). Contrastingly, autistic children who use few to no words show greater ADHD severity scores (Lerner et al., 2018).

There has been limited research on how verbal language relates to, or impacts on, sensory reactivity. The limited research conducted thus far has found positive 
correlations between communicative difficulties and sensory reactivity severity. Specifically, this has been shown in sensory seeking and hypo-reactivity. Using measures of communicative ability, such as the communication domain of the Vineland Adaptive Behavior Scales (Sparrow et al., 1984), researchers have identified that as communicative difficulties increase, so too do sensory reactivity differences (Liss et al., 2006; Watson et al., 2011). More broadly, further studies investigating autism severity and sensory reactivity have revealed a positive relationship between autism severity and sensory reactivity (Adamson et al., 2006; Kern et al., 2007; Taylor et al., 2018). However, this area needs further exploration as other studies have found limited evidence of this link (Lane et al., 2014).

The current study seeks to explore sensory reactivity and mental health symptoms, and elucidate the correlational relationship between sensory reactivity and mental health constructs across autistic preschool-aged children presenting with a wide range of abilities. In line with recent research proposing studies should explore autism subgroups both separately and combined (Mottron \& Bzdok, 2020), our aim was to investigate mental health symptoms and sensory reactivity within our total sample prior to exploring any variations within the verbal and few to no words subgroups.

\section{METHODS}

\section{Participants}

Overall, 62 preschool-aged children were recruited through the University of Reading's Centre for Autism participant database, social media platforms, local National Health Service (NHS) Child and Adolescent Mental Health Services (CAMHS), word of mouth and through Autism Berkshire - a local autism organization. Inclusion criteria were either (a) having a standing clinical diagnosis of autism completed by a clinical psychologist and/or speech and language therapist and confirmed by a pediatrician, or (b) having a suspected autism spectrum condition (ASC) and meeting cut-off criteria on both the Autism Diagnostic Observation Schedule (ADOS-2) (Lord et al., 2012) and the Autism Quotient (AQ) (Auyeung et al., 2008). Eight participants were excluded as they did not have a standing clinical diagnosis of autism and scored below cut-off on the ADOS-2. Thus, in total 54 autistic children were included in our final analyses (41 males and 13 females, 3-5 years, $M=4.02, S D=0.77$ ).

For this data collection both the University of Reading Research Ethics Committee and the NHS Health Research Authority approved the consenting procedure used for these participants. Parents provided written consent, and verbal assent was obtained from children who were able to, otherwise voluntary task compliance was considered assent. All children were provided with social stories ahead of time depicting the testing activities, pictures of the buildings and campus, and photos of the researchers. Further steps taken to minimize participant anxiety or discomfort included a period of acclimation at the beginning of the testing session whereby participants engaged in free play, inclusion of parents within the testing room at all times, utilization of a visual timetable for the activities, and access to snacks and drinks. Fifty-one participants completed the ADOS-2 to confirm inclusion criteria. Of these, 32 children completed Module 1 and 19 children completed Module 2. The remaining three participants had received a community diagnosis of autism, which included the ADOS-2, within the 6 months prior to testing. One of these participants completed Module 1, and the other two completed Module 2. Overall, 33 children completed Module 1 and 21 children completed module 2 .

To contextualize our sample, we conducted the Matrix Reasoning subtests of the Wechsler Nonverbal Scale of Ability (WNV) (Wechsler, 2006) for those aged four or five, or the British Ability Scale (BAS3) (Eliot \& Smith, 2011) for those aged three. Participants who were able to engage and complete cognitive testing had a mean Matrix Reasoning $T$-score of 53.67 (range: 17-72, $S D=13.59$ ). However, only 21 participants were able to complete cognitive testing, and as such this score may be an over- or under-estimation of the true mean, although caution should be taken if underestimating the intelligence of autistic individuals who use few to no words (Courchesne et al., 2019; Giofrè et al., 2019). None of the participants had any sight or hearing impairments that would impact their performance in the study. One participant reported comorbid avoidant restrictive food intake disorder (ARFID), one participant reported a comorbid autosomal disorder (Currarino triad) and one participant reported a chromosome disorder (16p11.2 deletion syndrome). Fifty-two participant families provided ethnic background data, and the sample was reported as Caucasian (64.8\%), South Asian (20.4\%), North African (1.9\%) and Mixed (9.3\%). Demographic characteristics can be further found in Table 1 .

\section{Mental health measure}

\section{Behavior Assessment System for Children Third Edition-Parent Rating Scale-Preschool (BASC-3 PRS-P)}

The BASC-3 PRS-P is a parent-completed measure of adaptive and maladaptive behaviors in children aged two to five. The measure contains 12 subscales, four composite scales, nine content scales and four executive functioning indices (Reynolds \& Kamphaus, 2015), with each item utilizing a 4-point Likert-type scale ("Never" to "Almost Always"). This study used five subscales 
T A B L E 1 Demographic characteristics of participants

\begin{tabular}{|c|c|c|c|c|c|c|c|c|}
\hline Participants & $N$ & $\%$ & Mean age (Y:M) & SD (Y:M) ${ }^{a}$ & Range & & & \\
\hline Female & 13 & 24.07 & $3.92(3: 11)$ & $0.76(0: 9)$ & $3-5$ & & & \\
\hline \multirow[t]{2}{*}{ ADOS-2 module } & \multicolumn{2}{|c|}{ Total } & \multirow[b]{2}{*}{ Mean age $(\mathrm{Y}: \mathrm{M})^{\mathbf{a}}$} & \multirow[b]{2}{*}{$\mathbf{S D}(\mathbf{Y}: \mathbf{M})^{\mathbf{a}}$} & \multicolumn{2}{|l|}{ Female } & \multicolumn{2}{|c|}{ Male } \\
\hline & $N$ & $\%$ & & & $N$ & $\%$ & $N$ & $\%$ \\
\hline Module 2 (verbal) & 21 & 38.88 & $4.19(4: 2)$ & $0.81(0: 9)$ & 5 & 23.81 & 16 & 76.19 \\
\hline Matrix reasoning & $N$ & $\%$ & Mean T score & SD & Range & & & \\
\hline Total & 21 & 38.89 & 53.67 & 13.59 & $17-72$ & & & \\
\hline Few to no words & 6 & 18.75 & 52.2 & 12.79 & $33-64$ & & & \\
\hline Verbal & 15 & 78.95 & 53.73 & 14.61 & $17-72$ & & & \\
\hline North African & 1 & 1.9 & & & & & & \\
\hline Mixed & 5 & 9.3 & & & & & & \\
\hline Unreported & 2 & 3.7 & & & & & & \\
\hline
\end{tabular}

${ }^{\mathrm{a}}$ (Years: Months).

(hyperactivity, aggression, anxiety, depression, and somatisation) and two composite scales (internalizing problems and externalizing problems). Subscale example questions for hyperactivity include "acts without thinking" and "has poor self-control;" for aggression include "breaks other children's things" and "hits other children;" for anxiety include "is nervous" and "is easily stressed;" for depression include "cries easily" and "is easily upset;" and for somatisation include "vomits" and "has sore throats." Raw scores for each scale are summed and transformed into standardized $T$-scores $(M=50$; $S D=10$ ) for interpretation. The BASC-3 PRS-P has been found to have both strong internal consistency (Cronbach's $\alpha=0.83-0.93$ across composites and scales) and test-retest reliability ( $r=0.87-0.92$ across composites and scales) (Reynolds \& Kamphaus, 2015). It is noted that the BASC has been widely used in autism research (Bradstreet et al., 2017; Ellison et al., 2019; Gardner et al., 2018; Lindsey et al., 2020; Mahan \& Matson, 2011; Volker et al., 2010).

\section{Sensory reactivity measures}

\section{Sensory Processing Scale Inventory (SPSI)}

The SPSI is a parent-report measure of sensory overresponsivity (SOR; aka hyper-reactivity), underresponsivity (SUR; aka hypo-reactivity), and sensory craving (SC; aka sensory seeking) (Schoen et al., 2017). The measure consists of sensory behavioral items matched to the three sensory constructs. Example items for hyper-reactivity include "These aspects of self-care bother my child (e.g., getting dressed, washing or wiping face);" for hypo-reactivity include "Typically my child does not notice (e.g., hands or face that are messy, activity in a busy environment);" and for sensory seeking include "My child likes to (e.g., make a lot of noises during play activity; often makes strange sounds)." Responses are rated on a binary scoring system (applicable $=1$; not applicable $=0$ ), then summed to provide total construct scores. Internal consistency was strong across all scales (SOR: $\alpha=0.89$; SUR: $\alpha=0.88$; SC: $\alpha=0.93$ ) (Schoen et al., 2017).

\section{Sensory Assessment of Neurodevelopmental Differences (SAND)}

The SAND (Siper et al., 2017) is a measure of sensory reactivity consisting of a direct observation and corresponding caregiver interview that is appropriate for children with few to no words. The direct observation involves the standardized presentation of 15 specific sensory stimuli (in the form of child-friendly toys; five for each modality - visual, tactile, and auditory) to participants with a trained administrator rating corresponding behavioral responses. The interview requires caregivers to answer questions on their child's sensory preferences which are item-matched to the observation. Both the observation and interview provide construct scores for hyper-reactivity, hypo-reactivity and sensory seeking (range 0-24). Scores on both measures are dichotomous, 0 (not present) or 1 (present), based on observed or 
reported sensory behaviors. Severity scores are also coded $(1=$ mild; $2=$ moderate-severe $)$. The SAND has been used in autistic children who have few to no words, and has strong internal consistency (Cronbach's $\alpha=0.90$ ) and test-retest reliability $(r=0.82-0.97)$ (Siper et al., 2017). For a more detailed description of the SAND, please see Siper et al. (2017).

\section{RESULTS}

SPSS 24 was used to analyze the data. Pearson's correlation analysis was used to elucidate the relationship between the SPSI and the SAND. Relationships were found between each of the related constructs: hyperreactivity $\left(r_{\mathrm{s}}=0.55, \quad p<0.001\right)$, hypo-reactivity $\left(r_{\mathrm{s}}=0.33, p=0.016\right)$ and sensory seeking $\left(r_{\mathrm{s}}=0.36\right.$, $p=0.008)$. Given the relatedness of the measures, $z$ scores were calculated to standardize the data for analysis. Following standardization, composite scores were derived by summing and averaging SPSI and SAND $z$ scores in order to minimize multiple comparisons (Kim \& Lord, 2012; Song et al., 2013) and provide more robust sensory data which incorporates both parent-reports and observations as suggested in previous research (Siper et al., 2017; Tavassoli et al., 2016, 2019). Further, aggregating the data provides greater stability, representation, and estimation as measurement error is minimized (Rushton et al., 1983). The $z$-scores from the two sensory measures were combined and averaged to compute the composite, and the composite scores have been used for all subsequent analyses. A Shapiro-Wilk test indicated the following BASC subscales departed from normality: aggression $[W(50)=0.916, p=0.002]$, anxiety $[W$ $(50)=0.892, \quad p<0.001]$, and somatisation $[W$ $(50)=0.922, p=0.003]$. As such nonparametric tests have been used to analyze the relationship between sensory scores and BASC-2 mental health constructs.

\section{Descriptive analyses}

Frequencies of participants meeting clinical threshold for behavioral and mental health symptoms were determined in order to assess prevalence rates of hyperactivity, aggression, externalizing problems, anxiety, depression, somatisation, and internalizing problems in our sample. As per Reynolds and Kamphaus (2015), clinically indicated scores are determined as a $T$-score of 70 or higher in the domains assessed, representing less than $5 \%$ of the population. Results are shown in Table 2, along with sensory reactivity and ADOS-2 comparison score descriptives.

$46.3 \%$ of our sample scored in the clinically significant range for hyperactivity (verbal $=47.6 \%$, few to no words $=45.5 \%$ ), $31.5 \%$ for aggression (verbal $=38.1 \%$, few to no words $=27.3 \%$ ), $40.7 \%$ for externalizing problems $($ verbal $=52.4 \%$, few to no words $=33.3 \%), 13.0 \%$ for anxiety (verbal $=23.8 \%$, few to no words $=6.1 \%$ ),
$25.9 \%$ for depression (verbal $=38.1 \%$, few to no words $=18.2 \%), 14.8 \%$ for somatisation $($ verbal $=19.0 \%$, few to no words $=12.1 \%$ ), and $20.4 \%$ for internalizing problems $($ verbal $=23.8 \%$, few to no words $=18.2 \%$ ). Further, $69.4 \%$ of our sample scored within the clinically significant range for at least one symptom (verbal $=71.4 \%$, few to no words $=69.7 \%$ ), with $56.4 \%$ scoring within the clinically significant range for two or more symptoms (verbal $=61.9 \%$, few to no words $=54.5 \%$ ). A Wilcoxon signed-rank test indicated our sample was more likely to present with an externalizing problem than an internalizing problem $(Z=-5.72, p<0.001)$.

\section{Sensory reactivity and mental health symptoms}

In order to examine the relationship between sensory reactivity differences and behavior and mental health symptoms in the overall sample, bivariate correlational analyses were conducted between the sensory composite $z$-scores and BASC-3 $z$-scores using Spearman's correlations (Table 3).

\section{Hyper-reactivity and mental health}

Small to moderate positive effects were detected for anxiety $\left(r_{\mathrm{s}}=0.30,95 \% \mathrm{CI}[0.012,0.577], p=0.033\right)$, depression $\left(r_{\mathrm{s}}=0.33,95 \%\right.$ CI $\left.[0.034,0.571], p=0.021\right)$, somatisation $\left(r_{\mathrm{s}}=0.52,95 \%\right.$ CI $[0.259,0.720]$, $p<0.001)$, and internalizing problems $\left(r_{\mathrm{s}}=0.43,95 \% \mathrm{CI}\right.$ $[0.156,0.654], p=0.002)$.

\section{Hypo-reactivity and mental health}

A moderate negative effect was detected for anxiety $\left(r_{\mathrm{s}}=-0.44,95 \% \mathrm{CI}[-0.668,-0.153], p=0.001\right)$.

\section{Sensory seeking and mental health}

Moderate to large positive effects were detected for hyperactivity $\quad\left(r_{\mathrm{s}}=0.68,95 \%\right.$ CI $[0.490,0.8 .6]$, $p<0.001)$, aggression $\left(r_{\mathrm{s}}=0.47,95 \%\right.$ CI [0.226, 0.688], $p=0.001)$, externalizing problems $\left(r_{\mathrm{s}}=0.60,95 \% \mathrm{CI}\right.$ [0.381, 0.776], $p<0.001)$, and depression $\left(r_{\mathrm{s}}=0.33,95 \%\right.$ CI $[0.074,0.566], p=0.021)$.

We subsequently examined if ADOS-2 comparison scores or total AQ scores, representing autism traits, were related to sensory or mental health symptoms. Spearman's correlation analysis indicated that AQ and ADOS-2 comparison scores were significantly positively correlated with aggression, externalizing problems, anxiety and internalizing problems. Post-hoc partial correlation analysis controlling for autism traits found that all correlations between sensory composites and mental health symptoms remained significant $(p<0.05)$. 
T A B L E 2 Descriptive statistics for sensory reactivity differences (SPSI and SAND raw scores; z-score composites), mental health symptoms (BASC-3 raw scores, and percentage of participants who scored above the cut off indicating clinically elevated symptom severity), and autism traits (ADOS-2 raw comparison scores)

\begin{tabular}{|c|c|c|c|c|c|c|c|c|c|}
\hline & \multicolumn{2}{|l|}{ Total } & \multicolumn{2}{|l|}{ Verbal } & \multicolumn{2}{|c|}{ Few to no words } & \multicolumn{3}{|c|}{ Clinically elevated (\%) } \\
\hline \multicolumn{10}{|l|}{ SPSI } \\
\hline Hyper-reactivity & 12.7 & 5.7 & 13.3 & 5.5 & 12.3 & 5.9 & - & - & - \\
\hline Hypo-reactivity & 11.1 & 4.9 & 9.3 & 4.7 & 12.3 & 4.7 & - & - & - \\
\hline Sensory Seeking & 9.9 & 5.1 & 10.0 & 6.0 & 9.9 & 4.6 & - & - & - \\
\hline Hyper-reactivity & 9.4 & 3.7 & 9.3 & 4.1 & 9.5 & 3.7 & - & - & - \\
\hline Hypo-reactivity & 8.5 & 5.6 & 5.6 & 4.2 & 10.4 & 5.6 & - & - & - \\
\hline Sensory Seeking & 17.6 & 3.6 & 16.7 & 6.3 & 18.1 & 3.1 & - & - & - \\
\hline \multicolumn{10}{|l|}{ BASC-3 } \\
\hline Hyperactivity & 22.9 & 6.0 & 23.0 & 6.3 & 22.8 & 5.9 & 46.3 & 47.6 & 45.5 \\
\hline Depression & 12.8 & 6.2 & 14.1 & 6.9 & 11.9 & 5.5 & 25.9 & 38.1 & 18.2 \\
\hline Somatisation & 8.6 & 6.2 & 8.4 & 7.7 & 8.7 & 4.9 & 14.8 & 19.0 & 12.1 \\
\hline Internalizing Problems & 169.5 & 34.0 & 179.0 & 36.1 & 162.9 & 31.4 & 20.4 & 23.8 & 18.2 \\
\hline \multicolumn{10}{|l|}{ ADOS-2 } \\
\hline Comparison Score & 6.2 & 2.8 & 7.2 & 2.3 & 4.5 & 2.7 & - & - & - \\
\hline
\end{tabular}

T A B L E 3 Correlations between sensory composites (SPSI and SAND), and behavior and mental health symptoms (BASC-3) for combined groups $(\mathrm{n}=54)$

\begin{tabular}{|c|c|c|c|c|c|c|}
\hline & \multicolumn{2}{|c|}{ Hyper-reactivity } & \multicolumn{2}{|c|}{ Hypo-reactivity } & \multicolumn{2}{|c|}{ Sensory seeking } \\
\hline Hyperactivity & 0.21 & 0.14 & 0.08 & 0.56 & 0.68 & 0.00 \\
\hline Aggression & 0.18 & 0.20 & -0.12 & 0.42 & 0.47 & 0.00 \\
\hline Externalizing problems & 0.16 & 0.27 & -0.04 & 0.79 & 0.60 & 0.00 \\
\hline Anxiety & 0.30 & 0.03 & -0.44 & 0.00 & 0.15 & 0.30 \\
\hline Somatization & 0.52 & 0.00 & 0.10 & 0.48 & 0.12 & 0.42 \\
\hline Internalizing problems & 0.43 & 0.00 & -0.20 & 0.15 & 0.23 & 0.10 \\
\hline
\end{tabular}

Note: SPSI = Sensory Processing Scale Inventory; SAND = Sensory Assessment of Neurodevelopmental Differences; BASC-3 = Behavior Assessment System for Children, 3rd Edition.

Further, Fisher's $z$-test confirmed that the changes in correlation coefficients were not significant $(p>0.05)$, suggesting the relationships are independent from the effects of autism traits.

\section{Sensory reactivity and mental health symptoms by subgroup}

In order to examine the relationship between sensory reactivity differences and behavior and mental health symptoms between verbal participant and participants with few to no words, bivariate correlational analyses were conducted between the sensory composite $z$-scores and BASC-3 $z$-scores using Spearman's correlations (Tables 4 and 5).

\section{Hyper-reactivity and mental health}

In the few to no words group, moderate to large positive effects were detected for anxiety $\left(r_{\mathrm{s}}=0.60,95 \% \mathrm{CI}\right.$ $[0.268,0.768], p=0.001)$, depression $\left(r_{\mathrm{s}}=0.57,95 \%\right.$ CI $[0.224,0.772], p=0.001)$, somatisation $\left(r_{\mathrm{s}}=0.62\right.$, 
T A B L E 4 Correlations between sensory composites (SPSI and SAND), and behavior and mental health symptoms (BASC-3) for the verbal $\operatorname{group}(\mathrm{n}=21)$

\begin{tabular}{|c|c|c|c|c|c|c|}
\hline & \multicolumn{2}{|c|}{ Hyper-reactivity } & \multicolumn{2}{|c|}{ Hypo-reactivity } & \multicolumn{2}{|c|}{ Sensory seeking } \\
\hline & $r$ & $p$ & $\boldsymbol{r}$ & $p$ & $\boldsymbol{r}$ & $p$ \\
\hline Hyperactivity & 0.04 & 0.86 & 0.24 & 0.29 & 0.74 & 0.00 \\
\hline Aggression & 0.02 & 0.93 & -0.01 & 0.97 & 0.59 & 0.01 \\
\hline Externalizing problems & 0.02 & 0.92 & 0.13 & 0.56 & 0.71 & 0.00 \\
\hline Anxiety & 0.02 & 0.92 & -0.34 & 0.13 & 0.27 & 0.23 \\
\hline Depression & 0.04 & 0.85 & -0.08 & 0.72 & 0.38 & 0.09 \\
\hline Somatization & 0.32 & 0.15 & 0.22 & 0.35 & 0.13 & 0.58 \\
\hline Internalizing problems & 0.21 & 0.35 & -0.02 & 0.93 & 0.34 & 0.13 \\
\hline
\end{tabular}

Note: SPSI = Sensory Processing Scale Inventory; SAND = Sensory Assessment of Neurodevelopmental Differences; BASC-3 = Behavior Assessment System for Children, 3rd Edition.

T A B L E 5 Correlations between sensory composites (SPSI and SAND), and behavior and mental health symptoms (BASC-3) for the few to no words group $(\mathrm{n}=33)$

\begin{tabular}{|c|c|c|c|c|c|c|}
\hline & \multicolumn{2}{|c|}{ Hyper-reactivity } & \multicolumn{2}{|c|}{ Hypo-reactivity } & \multicolumn{2}{|c|}{ Sensory seeking } \\
\hline & $r$ & $p$ & $r$ & $p$ & $r$ & $p$ \\
\hline Hyperactivity & 0.34 & 0.08 & -0.07 & 0.73 & 0.62 & 0.00 \\
\hline Externalizing problems & 0.27 & 0.16 & -0.22 & 0.25 & 0.49 & 0.01 \\
\hline Anxiety & 0.60 & 0.00 & -0.38 & 0.04 & 0.09 & 0.64 \\
\hline Somatization & 0.62 & 0.00 & -0.13 & 0.52 & 0.07 & 0.71 \\
\hline Internalizing problems & 0.59 & 0.00 & -0.24 & 0.21 & 0.20 & 0.31 \\
\hline
\end{tabular}

Note: SPSI = Sensory Processing Scale Inventory; SAND = Sensory Assessment of Neurodevelopmental Differences; BASC-3 = Behavior Assessment System for Children, 3rd Edition.

$95 \%$ CI $[0.223,0.806], p<0.001)$, and internalizing problems $\left(r_{\mathrm{s}}=0.59,95 \%\right.$ CI $\left.[0.253,0.760], p=0.001\right)$. No effects were detected in the verbal group.

\section{Hypo-reactivity and mental health}

A moderate negative effect was detected for anxiety $\left(r_{\mathrm{s}}=-0.38,95 \%\right.$ CI [-0.694, -0.062$\left.], p=0.040\right)$ in the few to no words group. No effects were detected in the verbal group.

\section{Sensory seeking and mental health}

Moderate to large positive effects were detected in the externalizing domains for both groups, and depression in the few to no words group. For the few to no words group this included hyperactivity $\left(r_{\mathrm{s}}=0.62,95 \% \mathrm{CI}\right.$ [0.331, 0.805], $p<0.001)$, aggression $\left(r_{\mathrm{s}}=0.44,95 \% \mathrm{CI}\right.$ $[0.086,0.725], \quad p=0.018)$, externalizing problems $\left(r_{\mathrm{s}}=0.49,95 \% \mathrm{CI}[0.133,0.761], p=0.006\right)$, and depres$\operatorname{sion}\left(r_{\mathrm{s}}=0.38,95 \% \mathrm{CI}[0.055,0.644], p=0.041\right)$. For the verbal group this included hyperactivity $\left(r_{\mathrm{s}}=0.74,95 \%\right.$
CI $[0.320,0.880], p<0.001)$, aggression $\left(r_{\mathrm{s}}=0.59\right.$, $95 \%$ CI [0.136, 0.867], $p=0.005)$, and externalizing problems $\left(r_{\mathrm{s}}=0.71,95 \%\right.$ CI [0.255, 0.889], $\left.p<0.001\right)$.

\section{Sensory reactivity and mental health symptoms subgroup differences}

Using the Fisher $r$-to- $z$ transformation, we assessed the significance of the difference between correlation coefficients across the two groups. A difference was found between groups for hyper-reactivity and anxiety $(z=-2.23, p=0.012)$ and depression $(z=-2.09$, $p=0.018)$.

\section{DISCUSSION}

Using parent-report measures of mental health symptoms, and parent-report, interview, and observational measures of sensory reactivity, the objective of this study was to examine the relationship between sensory reactivity and mental health symptoms in autistic preschoolaged children. Our findings support that mental health 
symptoms are present in young autistic children and indicate a relationship between visual, tactile, and auditory reactivity and mental health. Moreover, findings highlight similarities as well as divergent relationships between mental health and sensory reactivity differences between autistic preschool-aged children who are verbal, and those who use few to no words.

In line with previous research, $70 \%$ of our sample showed elevated levels of mental health symptoms (American Psychiatric Association, 2013; Caamaño et al., 2013; Simonoff et al., 2008), with participants more likely to present with an externalizing problem than an internalizing problem. Over two-thirds of our sample scored within the clinically significant range for at least one symptom, and over half scored within the clinically significant range for two or more symptoms, with the most endorsed symptoms from within the externalizing problems domain.

At a sensory construct level, our results indicate that hyper-reactivity is significantly related to internalizing problems in autistic preschoolers. Our results echo the established understanding of the relationship between sensory hyper-reactivity and anxiety (Green et al., 2012; Green \& Ben-Sasson, 2010; Liss et al., 2005; MacLennan et al., 2020) and our combined data also shows more broadly a relationship of hyper-reactivity and internalizing symptoms. Our results are also in line with previous research showing an association between hyper-reactivity and somatic complaints (Beaudry-Bellefeuille et al., 2019; Lefter et al., 2020). However, the positive relationship seen between hyper-reactivity and depressive symptoms in our sample has not been shown in previous research, with extant literature thus far only having identified a relationship between hypo-reactivity and depressive symptoms in autistic children (Bitsika et al., 2016; Pfeiffer et al., 2005). The difference between previous findings and our findings may be due to differences in sample and methodology between our study and previous studies. Both Bitsika et al. (2016) and Pfeiffer et al. (2005) utilized an older sample, with a mean age of 11.2 years (range 6-18 years) and 9.8 years (range 617 years), respectively, whereas our sample was younger (mean age of 4.02 ; range 3-5 years). One hypothesis could be that sensory processing pathways or mechanisms may change over time in response to unpleasant sensory stimuli. For example, as a type of desensitization as the person becomes used to the sensory input. Our sample also included participants across the autistic spectrum, whilst previous studies did not include participants with few to no words. In our sample the relationship between hyper-reactivity and depression was driven by the subgroup of autistic children who use few to no words, and we further could not find a relationship between sensory hyper-reactivity and depressive symptoms in the verbal subgroup, which is in line with previous work (Bitsika et al., 2016; Pfeiffer et al., 2005).
Therefore, as previous work has only explored the relationship between sensory reactivity and depressive symptoms in older and verbal children, this work extends previous findings and highlights the need to explore the relationship between sensory reactivity and mental health constructs in autistic children with different language abilities. Our data suggests that symptoms of depression in young autistic children are driven by those who use few to no words. One explanation may be that verbal ability moderates the relationship between hyperreactivity and mental health symptoms. Namely, that autistic individuals utilize functional language to meet their sensory and/or mental health needs, with individuals who use few to no words unable to do so as efficiently. Further, individuals who use few to no words may have a reduced communicative ability to modify or control their environment to minimize distressing sensory input. It is therefore worth exploring functional language in prospective sensory and mental health autism research to elucidate this relationship. Further, differences in our findings of hypo-reactivity and depression when compared with previous research (Bitsika et al., 2016; Pfeiffer et al., 2005) may be an artifact of directionality or causality, which is beyond the scope of the current study.

We found little evidence of a relationship between hypo-reactivity and mental health symptoms outside of anxiety. Recent research investigating sensory hyporeactivity and anxiety report significant findings in their overall sample (MacLennan et al., 2020), with the authors positing that hypo-reactivity may serve as a defense against sensory overload and the corresponding evocation of anxiety symptoms. In our sample, the hyporeactivity/anxiety relationship, whilst significant in the total sample, did not hold significance when split by group. However, a relationship was seen at the trend level in both groups, with $r$ coefficients larger than 0.3. It is noted though that compared to other subscales, the BASC-3 anxiety subscale may be less accurate in investigating anxiety symptoms in those who use few to no words, as the wording of some items assumes the use of functional and/or verbal communication (e.g., says, "I'm not very good at this" or worries about what parents think).

We further found a relationship between sensory seeking and externalizing symptoms, including for hyperactivity and aggression, in our combined data, which held for both groups when split by verbal ability. Whilst causal inferences cannot be made from cross-sectional data, the nature of sensory seeking is such that seekers do not have their sensory needs met organically, and therefore must pursue such stimuli to meet those needs. Therefore, a potential argument could be made that from a construct level in autistic children with externalizing behaviors, the disparity of having a sensory need but not being able to effectively satisfy that need, even when one seeks out sensory stimuli, may be associated with the 
development of mental health symptomology. On the other hand, seeking could also be used as a coping mechanism to manage mental health symptoms and might have beneficial effects as anecdotal reports suggest, and would include seeking out sensory stimuli to support physiological, behavioral and emotional regulation.

This study was unique in that it explored the association between sensory reactivity differences and mental health symptoms across autistic children who are verbal and those who use few to no words. However, there are several limitations noted. It is worth highlighting that whilst there have been recent developments in sensory measures designed specifically for those who are neurodiverse and use few to no words (Siper et al., 2017), there is a general lack of validated measures of mental health and language ability when assessing across the entirety of the autism spectrum. Moreover, this also speaks to the wider issue of reliance on parent-report measures to the detriment of other measures, for example self-report, observation, or measures of physiology. This study utilized parent-report measures of mental health symptoms, and it is possible that there exists a bias towards over- or under-responding to mental health domains, or misattribution of related behaviors in responses (Stokes et al., 2011). Parents may also misattribute autistic behaviors or define behaviors through a non-autistic viewpoint, with further potential for behaviors driven by sensory differences to be inferred as symptoms assessed within mental health measures. It is also acknowledged that whilst the BASC-3 has previously been used in autism research and provides a foundation for understanding mental health symptoms in this cohort, caution should be taken when interpreting our results as it has yet to be validated in the autistic population, and includes items which may be difficult to answer for those who use few to no words (e.g., "speaks in short phrases that are hard to understand" or "says, "I'm not very good at this"'). It is considered highly appropriate that future research investigating mental health constructs in autism consider measures of mental health which have been specifically designed, or at least validated, with this population.

Further, whilst our sample size was in line with previous studies of sensory reactivity and mental health (Baranek et al., 2013; Leekam et al., 2007; Pfeiffer et al., 2005), the subgroup sample size may not be an accurate representation of larger ASC cohorts. Due to sample size and data limitations, we were not able to explore possible gender or socioeconomic differences between groups. Nevertheless, demographic risk factors may influence the emergence or trajectory of sensory reactivity or mental health symptoms, and we were unable to evaluate the role of these risk factors on our sensory and mental health variables.

It is noted that whilst the broad term of sensory reactivity has been used in this article, the composite utilizes data from three sensory domains and does not include data from other domains, such as interoception. As such, the authors make no assumptions about using the term sensory reactivity as an absolute. Moreover, whilst it is beyond the scope of this article to discuss the other sensory domains, such as olfaction, proprioception or interoception in detail, there is emerging evidence for the relationship between other sensory domains and mental health (e.g., Palser et al., 2018; Trevisan et al., 2020). Future studies should consider including other sensory domains.

Our findings have implications for interventions with young autistic children. Sensory reactivity appears to be related to the symptoms of mental health, and it may be beneficial to assess sensory differences as part of more rigorous mental health assessments within mental health services. Additionally, it is worth considering sensory needs within educational, community, and clinical settings, particularly when children are presenting with comorbid mental health symptoms. This may then have repercussions, namely benefits, for the development of more robust support plans and interventions. From a research perspective, it is critical for future studies to explore the underpinnings of the sensorymental health relationship in individuals who use few to no words. It is also critical to understand the causal relationship between sensory reactivity and mental health, particularly with hyper-reactivity and sensory seeking using longitudinal research. This should include an exploration of the degree to which sensory reactivity is a product of mental health difficulties, and conversely the degree to which mental health difficulties are a product of sensory reactivity. A greater understanding of the causal direction would allow for the exploration of whether addressing sensory needs in children presenting with autism early may be a key component in preventative mental health interventions. Further, research could also explore potential additional variable relationships, such as sensory constructs as mediators or moderators, or the role of other factors such as stress or intolerance of uncertainty. Studies with larger sample sizes which include analyzable numbers of female participants are required to replicate and fully understand the sensory-mental health relationship. This future research should incorporate measures that are validated across the autistic spectrum.

\section{CONCLUSION}

The objectives of this study were to explore the association between sensory reactivity differences and mental health symptoms in autistic children. There appears to be a relationship between sensory reactivity and mental health symptoms in autistic children. Specifically, sensory seeking and externalizing symptoms, and hyper-reactivity and internalizing symptoms in autistic preschoolers who use few to no words. 


\section{ACKNOWLEDGMENTS}

Special thanks to all the families who participated. Thanks to Francesca Englezou, Charlotte Daniels, and Khadija Kapadia of the University of Reading for assisting with data collection, and the Centre for Autism at the University of Reading, Autism Berkshire, and Berkshire Healthcare Foundation Trust CAMHS for helping with recruitment. The authors are funded by MQ: Transforming Mental Health and Autistica.

\section{CONFLICT OF INTEREST}

The authors have no conflicts of interest to declare.

\section{AUTHOR CONTRIBUTIONS}

Teresa Tavassoli conceived of the study. Timothy Rossow, Keren MacLennan and Teresa Tavassoli participated in its design, testing and data collection. Timothy Rossow performed the data analysis, interpretation and drafted the paper. Teresa Tavassoli and Keren MacLennan provided critical revisions. All authors approved the final version of the manuscript for submission.

\section{ETHICAL STATEMENT}

All procedures performed in studies involving human participants were in accordance with the ethical standards of the University of Reading Research Ethics Committee (18/44) and National Health System Health Research Authority (18/SC/0462).

\section{OR CID}

Timothy Rossow (D) https://orcid.org/0000-0002-0495-1933 Keren MacLennan (D) https://orcid.org/0000-0002-31483450

\section{ENDNOTE}

${ }^{1}$ Careful consideration was given to the language used within the manuscript, and the authors are highly conscious of the heterogeneity of people's preferences for the way autism, and people on the autistic spectrum, are described. Whilst there is no universally accepted preference for autism terminology, autism first language has been incorporated in line with research findings that indicate the majority of autistic people surveyed endorsed 'autism' or 'autistic' as their preferred terminology (Kenny et al., 2016) as well as checking directly with families who took part in this research.

\section{REFERENCES}

Adamson, A., O'Hare, A., \& Graham, C. (2006). Impairments in sensory modulation in children with autistic spectrum disorder. British Journal of Occupational Therapy, 69, 357-364. https://doi.org/10. 1177/030802260606900803

American Psychiatric Association. (2013). Diagnostic and statistical manual of mental disorders (DSM-5). American Psychiatric Pub.

Auyeung, B., Baron-Cohen, S., Wheelwright, S., \& Allison, C. (2008). The autism spectrum quotient: Children's version (AQ-child). Journal of Autism and Developmental Disorders, 38, 1230-1240. https://doi.org/10.1007/s10803-007-0504-z

Bailliard, A. L., \& Whigham, S. C. (2017). Linking neuroscience, function, and intervention: A scoping review of sensory processing and mental illness. American Journal of Occupational Therapy, 71, 7105100040p1. https://doi.org/10.5014/ajot.2017.024497
Baranek, G. T., Watson, L. R., Boyd, B. A., Poe, M. D., David, F. J., \& McGuire, L. (2013). Hyporesponsiveness to social and nonsocial sensory stimuli in children with autism, children with developmental delays, and typically developing children. Development and Psychopathology, 25(2), 307-320.

Bar-Shalita, T., Vatine, J. J., \& Parush, S. (2008). Sensory modulation disorder: A risk factor for participation in daily life activities. Developmental Medicine and Child Neurology, 50, 932-937. https:// doi.org/10.1111/j.1469-8749.2008.03095.x

Bartolomé-Villar, B., Mourelle-Martínez, M. R., Diéguez-Pérez, M., \& de Nova-García, M. J. (2016). Incidence of oral health in paediatric patients with disabilities: Sensory disorders and autism spectrum disorder systematic review II. Journal of Clinical and Experimental Dentistry, 8(3), e344-e351. https://doi.org/10.4317/ jced.52923

Beaudry-Bellefeuille, I., Lane, A., Ramos-Polo, E., \& Lane, S. J. (2019). Examining hyper-reactivity to defecation related sensations in children with functional defecation disorders. Annals of Colorectal Research, 7(4), 1-7.

Beaudry-Bellefeuille, I., \& Lane, S. J. (2017). Examining sensory overresponsiveness in preschool children with retentive fecal incontinence. American Journal of Occupational Therapy, 71, 7105220020p1. https://doi.org/10.5014/ajot.2017.022707

Bitsika, V., Sharpley, C. F., \& Mills, R. (2016). Are sensory processing features associated with depressive symptoms in boys with an ASD? Journal of Autism and Developmental Disorders, 46(1), 242252. https://doi.org/10.1007/s10803-015-2569-4

Boterberg, S., \& Warreyn, P. (2016). Making sense of it all: The impact of sensory processing sensitivity on daily functioning of children. Personality and Individual Differences, 92, 80-86. https://doi.org/ 10.1016/j.paid.2015.12.022

Bradstreet, L. E., Juechter, J. I., Kamphaus, R. W., Kerns, C. M., \& Robins, D. L. (2017). Using the BASC-2 parent rating scales to screen for autism spectrum disorder in toddlers and preschool-aged children. Journal of Abnormal Child Psychology, 45, 359-370. https://doi.org/10.1007/s10802-016-0167-3

Brown, C., Cromwell, R. L., Filion, D., Dunn, W., \& Tollefson, N. (2002). Sensory processing in schizophrenia: Missing and avoiding information. Schizophrenia Research, 55, 187-195. https://doi.org/ 10.1016/S0920-9964(01)00255-9

Caamaño, M., Boada, L., Merchán-Naranjo, J., Moreno, C., Llorente, C., Moreno, D., Arango, C., \& Parellada, M. (2013). Psychopathology in children and adolescents with ASD without mental retardation. Journal of Autism and Developmental Disorders, 43(10), 2442-2449. https://doi.org/10.1007/s10803-013-1792-0

Carr, J. L., Agnihotri, S., \& Keightley, M. (2010). Sensory processing and adaptive behavior deficits of children across the fetal alcohol spectrum disorder continuum. Alcoholism: Clinical and Experimental Research, 34(6), 1022-1032. https://doi.org/10.1111/j.15300277.2010.01177.x

Carter, A. S., Briggs-Gowan, M. J., Jones, S. M., \& Little, T. D. (2003). The infant-toddler social and emotional assessment (ITSEA): Factor structure, reliability, and validity. Journal of Abnormal Child Psychology, 31(5), 495-514. https://doi.org/10.1023/A: 1025449031360

Cermak, S. A., Curtin, C., \& Bandini, L. G. (2010). Food selectivity and sensory sensitivity in children with autism Spectrum disorders. Journal of the American Dietetic Association, 110, 238-246. https:// doi.org/10.1016/j.jada.2009.10.032

Courchesne, V., Girard, D., Jacques, C., \& Soulières, I. (2019). Assessing intelligence at autism diagnosis: Mission impossible? Testability and cognitive profile of autistic preschoolers. Journal of Autism and Developmental Disorders, 49, 845-856. https://doi.org/ 10.1007/s10803-018-3786-4

Cupelli, E. T., Escallier, L., Galambos, N., Xiang, S., \& Franco, I. (2014). Sensory processing differences and urinary incontinence in school-aged children. Journal of Pediatric Urology, 10, 880-885. https://doi.org/10.1016/j.jpurol.2014.01.002 
Dean, E. E., Little, L., Tomchek, S., \& Dunn, W. (2018). Sensory processing in the general population: Adaptability, resiliency, and challenging behavior. American Journal of Occupational Therapy, 72, 7201195060p1. https://doi.org/10.5014/ajot.2018.019919

Eliot, C. D., \& Smith, P. (2011). British ability scales, BAS3. GL Assessment.

Ellison, K., Bundy, M. B., Gore, J., \& Wygant, D. (2019). Exploration of the DSM-5's autism Spectrum disorder severity level specifier and prediction of autism severity. Exceptionality, 27, 289-298. https://doi.org/10.1080/09362835.2019.1579721

Engel-Yeger, B., Muzio, C., Rinosi, G., Solano, P., Geoffroy, P. A., Pompili, M., Amore, M., \& Serafini, G. (2016). Extreme sensory processing patterns and their relation with clinical conditions among individuals with major affective disorders. Psychiatry Research, 236, 112-118. https://doi.org/10.1016/j.psychres.2015. 12.022

Fok, M., \& Bal, V. H. (2019). Differences in profiles of emotional behavioral problems across instruments in verbal versus minimally verbal children with autism spectrum disorder. Autism Research, 12, 1367-1375. https://doi.org/10.1002/aur.2126

Gardner, L. M., Campbell, J. M., Bush, A. J., \& Murphy, L. (2018). Comparing behavioral profiles for autism Spectrum disorders and intellectual disabilities using the BASC-2 parent rating scalespreschool form. Journal of Psychoeducational Assessment, 36, 535551. https://doi.org/10.1177/0734282916689438

Giofrè, D., Provazza, S., Angione, D., Cini, A., Menazza, C., Oppi, F., \& Cornoldi, C. (2019). The intellectual profile of children with autism spectrum disorders may be underestimated: A comparison between two different batteries in an Italian sample. Research in Developmental Disabilities, 90, 72-79. https://doi.org/ 10.1016/j.ridd.2019.04.009

Gjevik, E., Eldevik, S., Fjæran-Granum, T., \& Sponheim, E. (2011). Kiddie-SADS reveals high rates of DSM-IV disorders in children and adolescents with autism spectrum disorders. Journal of Autism and Developmental Disorders, 41, 761-769. https://doi.org/10.1007/ s10803-010-1095-7

Glod, M., Riby, D. M., Honey, E., \& Rodgers, J. (2015). Psychological correlates of sensory processing patterns in individuals with autism Spectrum disorder: A systematic review. Review Journal of Autism and Developmental Disorders, 2(2), 199-221. https://doi. org/10.1007/s40489-015-0047-8

Goldsmith, H. H., Van Hulle, C. A., Arneson, C. L., Schreiber, J. E., \& Gernsbacher, M. A. (2006). A population-based twin study of parentally reported tactile and auditory defensiveness in young children. Journal of Abnormal Child Psychology, 34, 393-407. https://doi.org/10.1007/s10802-006-9021-3

Gouze, K. R., Hopkins, J., LeBailly, S. A., \& Lavigne, J. V. (2009). Reexamining the epidemiology of sensory regulation dysfunction and comorbid psychopathology. Journal of Abnormal Child Psychology, 37, 1077-1087. https://doi.org/10.1007/s10802-009-9333-1

Green, S. A., \& Ben-Sasson, A. (2010). Anxiety disorders and sensory over-responsivity in children with autism spectrum disorders: Is there a causal relationship? Journal of Autism and Developmental Disorders, 40, 1495-1504. https://doi.org/10.1007/s10803-0101007-x

Green, S. A., Ben-Sasson, A., Soto, T. W., \& Carter, A. S. (2012). Anxiety and sensory over-responsivity in toddlers with autism spectrum disorders: Bidirectional effects across time. Journal of Autism and Developmental Disorders, 42, 1112-1119. https://doi.org/10.1007/ s10803-011-1361-3

Harrison, L. A., Kats, A., Williams, M. E., \& Aziz-Zadeh, L. (2019). The importance of sensory processing in mental health: A proposed addition to the research domain criteria (RDoC) and suggestions for RDoC 2.0. Frontiers in Psychology, 10, 1-15. https:// doi.org/10.3389/fpsyg.2019.00103

Hilton, C., Graver, K., \& LaVesser, P. (2007). Relationship between social competence and sensory processing in children with high functioning autism spectrum disorders. Research in Autism
Spectrum Disorders, 1(2), 164-173. https://doi.org/10.1016/j.rasd. 2006.10.002

Hilton, C. L., Harper, J. D., Kueker, R. H., Lang, A. R., Abbacchi, A. M., Todorov, A., \& Lavesser, P. D. (2010). Sensory responsiveness as a predictor of social severity in children with high functioning autism spectrum disorders. Journal of Autism and Developmental Disorders, 40, 937-945. https://doi.org/10.1007/ s10803-010-0944-8

Hollway, J. A., Aman, M. G., \& Butter, E. (2013). Correlates and risk markers for sleep disturbance in participants of the autism treatment network. Journal of Autism and Developmental Disorders, 43, 2830-2843. https://doi.org/10.1007/s10803-013-1830-y

Jack, A., \& Pelphrey, A. (2017). Annual research Review: Understudied populations within the autism spectrum - current trends and future directions in neuroimaging research. Journal of Child Psychology and Psychiatry and Allied Disciplines, 58(4), 411-435. https://doi. org/10.1111/jcpp. 12687

Javitt, D. C. (2009). Sensory processing in schizophrenia: Neither simple nor intact. Schizophrenia Bulletin, 35, 1059-1064. https://doi.org/ $10.1093 / \mathrm{schbul} / \mathrm{sbp} 110$

Javitt, D. C., \& Freedman, R. (2015). Sensory processing dysfunction in the personal experience and neuronal machinery of schizophrenia. American Journal of Psychiatry, 172, 17-31. https://doi.org/10. 1176/appi.ajp.2014.13121691

Kenny, L., Hattersley, C., Molins, B., Buckley, C., Povey, C., \& Pellicano, E. (2016). Which terms should be used to describe autism? Perspectives from the UKautism community. Autism, 20 (4), 442-462. https://doi.org/10.1177/1362361315588200

Kern, J. K., Trivedi, M. H., Grannemann, B. D., Garver, C. R., Johnson, D. G., Andrews, A. A., Savla, S. J., Mehta, J. A., \& Schroeder, J. L. (2007). Sensory correlations in autism. Autism, 11, 123-134. https://doi.org/10.1177/1362361307075702

Kim, S. H., \& Lord, C. (2012). Combining information from multiple sources for the diagnosis of autism spectrum disorders for toddlers and young preschoolers from 12 to 47 months of age. Journal of Child Psychology and Psychiatry and Allied Disciplines, 53, 143151. https://doi.org/10.1111/j.1469-7610.2011.02458.x

Kreiser, N. L., \& White, S. W. (2015). ASD traits and co-occurring psychopathology: The moderating role of gender. Journal of Autism and Developmental Disorders, 45(12), 3932-3938. https://doi.org/ 10.1007/s10803-015-2580-9

Lai, M. C., Kassee, C., Besney, R., Bonato, S., Hull, L., Mandy, W., Szatmari, P., \& Ameis, S. H. (2019). Prevalence of co-occurring mental health diagnoses in the autism population: A systematic review and meta-analysis. The Lancet Psychiatry, 6, 819-829. https://doi.org/10.1016/S2215-0366(19)30289-5

Lane, A. E., Molloy, C. A., \& Bishop, S. L. (2014). Classification of children with autism spectrum disorder by sensory subtype: A case for sensory-based phenotypes. Autism Research, 7, 322-333. https://doi.org/10.1002/aur.1368

Lane, A. E., Young, R. L., Baker, A. E. Z., \& Angley, M. T. (2010). Sensory processing subtypes in autism: Association with adaptive behavior. Journal of Autism and Developmental Disorders, 40, 112 122. https://doi.org/10.1007/s10803-009-0840-2

Leekam, S. R., Nieto, C., Libby, S. J., Wing, L., \& Gould, J. (2007). Describing the sensory abnormalities of children and adults with autism. Journal of Autism and Developmental Disorders, 37, 894 910. https://doi.org/10.1007/s10803-006-0218-7

Lefter, R., Ciobica, A., Timofte, D., Stanciu, C., \& Trifan, A. (2020). A descriptive review on the prevalence of gastrointestinal disturbances and their multiple associations in autism spectrum disorder. Medicina (Lithuania), 56(1), 11-27. https://doi.org/10.3390/ medicina56010011

Lerner, M. D., Mazefsky, C. A., Weber, R. J., Transue, E., Siegel, M., Gadow, K. D., Erickson, C., Gabriels, R. L., Kaplan, D., Morrow, E. M., Righi, G., Santangelo, S. L., Wink, L., Benevides, J., Beresford, C., Best, C., Bowen, K., Dechant, B., Flis, T., ... Williams, D. (2018). Verbal ability and psychiatric 
symptoms in clinically referred inpatient and outpatient youth with ASD. Journal of Autism and Developmental Disorders, 48, 36893701. https://doi.org/10.1007/s10803-017-3344-5

Lindsey, R. A., Saltness, S. R., Lau, A. F., \& Barry, T. D. (2020). A longitudinal examination of interactions between autism symptom severity and parenting behaviors in predicting change in child behavior problems. Research in Autism Spectrum Disorders, 70, 101469. https://doi.org/10.1016/j.rasd.2019.101469

Liss, M., Mailloux, J., \& Erchull, M. J. (2008). The relationships between sensory processing sensitivity, alexithymia, autism, depression, and anxiety. Personality and Individual Differences, 45, 255-259. https://doi.org/10.1016/j.paid.2008.04.009

Liss, M., Saulnier, C., Fein, D., \& Kinsbourne, M. (2006). Sensory and attention abnormalities in autistic spectrum disorders. Autism, 10, 155-172. https://doi.org/10.1177/1362361306062021

Liss, M., Timmel, L., Baxley, K., \& Killingsworth, P. (2005). Sensory processing sensitivity and its relation to parental bonding, anxiety, and depression. Personality and Individual Differences, 39, 14291439. https://doi.org/10.1016/j.paid.2005.05.007

Lord, C., Rutter, M., DiLavore, P. C., Risi, S., Gotham, K., \& Bishop, S. (2012). Autism diagnostic observation schedule (2nd ed.). Western Psychological Services. Western Psychological Services.

Lugnegård, T., Hallerbäck, M. U., \& Gillberg, C. (2011). Psychiatric comorbidity in young adults with a clinical diagnosis of Asperger syndrome. Research in Developmental Disabilities, 32, 1910-1917. https://doi.org/10.1016/j.ridd.2011.03.025

Lundström, S., Reichenberg, A., Melke, J., Råstam, M., Kerekes, N., Lichtenstein, P., Gillberg, C., \& Anckarsäter, H. (2015). Autism spectrum disorders and coexisting disorders in a nationwide Swedish twin study. Journal of Child Psychology and Psychiatry and Allied Disciplines, 56, 702-710. https://doi.org/10.1111/jcpp.12329

MacLennan, K., Roach, L., \& Tavassoli, T. (2020). The relationship between sensory reactivity differences and anxiety subtypes in autistic children. Autism Research, 13, 785-795. https://doi.org/10. 1002/aur.2259

Mahan, S., \& Matson, J. L. (2011). Children and adolescents with autism spectrum disorders compared to typically developing controls on the behavioral assessment system for children, second edition (BASC-2). Research in Autism Spectrum Disorders, 5, 119125. https://doi.org/10.1016/j.rasd.2010.02.007

Marco, E. J., Hinkley, L. B. N., Hill, S. S., \& Nagarajan, S. S. (2011). Sensory processing in autism: A review of neurophysiologic findings. Pediatric Research, 69, 48R-54R. https://doi.org/10.1203/ PDR.0b013e3182130c54

Margari, L., Palumbi, R., Peschechera, A., Craig, F., De Giambattista, C., Ventura, P., \& Margari, F. (2019). Sex-gender comparisons in comorbidities of children and adolescents with high-functioning autism spectrum disorder. Frontiers in Psychiatry, 10, 1-5. https://doi.org/10.3389/fpsyt.2019.00159

Mazurek, M. O., \& Petroski, G. F. (2015). Sleep problems in children with autism spectrum disorder: Examining the contributions of sensory over-responsivity and anxiety. Sleep Medicine, 16, 270279. https://doi.org/10.1016/j.sleep.2014.11.006

Miller, L. J., Anzalone, M. E., Lane, S. J., Cermak, S. A., \& Osten, E. T. (2007). Concept evolution in sensory integration: A proposed nosology for diagnosis. American Journal of Occupational Therapy, 61, 135-140. https://doi.org/10.5014/ajot.61.2.135

Mottron, L., \& Bzdok, D. (2020). Autism spectrum heterogeneity: Fact or artifact? Molecular Psychiatry, 25, 3178-3185. https://doi.org/ 10.1038/s41380-020-0748-y

Palser, E. R., Fotopoulou, A., Pellicano, E., \& Kilner, J. M. (2018). The link between interoceptive processing and anxiety in children diagnosed with autism spectrum disorder: Extending adult findings into a developmental sample. Biological Psychology, 136, 13-21. https://doi.org/10.1016/j.biopsycho.2018.05.003

Paterson, H., \& Peck, K. (2011). Sensory processing ability and eating behaviour in children with autism. Journal of Human Nutrition and
Dietetics, 24(3), 301. https://doi.org/10.1111/j.1365-277x.2011. 01175 31.x

Pfeiffer, B., Kinnealey, M., Reed, C., \& Herzberg, G. (2005). Sensory modulation and affective disorders in children and adolescents with Asperger's disorder. American Journal of Occupational Therapy, 59, 335-345. https://doi.org/10.5014/ajot.59.3.335

Reynolds, C. R., \& Kamphaus, R. W. (2015). Behavior assessment system for children manual ( $3 \mathrm{rd}$ ed.). Pearson.

Reynolds, S., Lane, S. J., \& Thacker, L. (2012). Sensory processing, physiological stress, and sleep behaviors in children with and without autism spectrum disorders. OTJR Occupation, Participation and Health, 32, 246-257. https://doi.org/10.3928/1539449220110513-02

Rushton, J. P., Brainerd, C. J., \& Pressley, M. (1983). Behavioral development and construct validity: The principle of aggregation. Psychological Bulletin, 94, 18-38. https://doi.org/10.1037/00332909.94.1.18

Russell, A. J., Murphy, C. M., Wilson, E., Gillan, N., Brown, C., Robertson, D. M., Craig, M. C., Deeley, Q., Zinkstok, J., Johnston, K., McAlonan, G. M., Spain, D., \& Murphy, D. G. M. (2016). The mental health of individuals referred for assessment of autism spectrum disorder in adulthood: A clinic report. Autism, 20, 623-627. https://doi.org/10.1177/1362361315604271

Schoen, S. A., Miller, L. J., \& Sullivan, J. (2017). The development and psychometric properties of the sensory processing scale Inventory: A report measure of sensory modulation. Journal of Intellectual and Developmental Disability, 42(1), 12-21. https://doi.org/10. 3109/13668250.2016.1195490

Serafini, G., Gonda, X., Canepa, G., Pompili, M., Rihmer, Z., Amore, M., \& Engel-Yeger, B. (2017). Extreme sensory processing patterns show a complex association with depression, and impulsivity, alexithymia, and hopelessness. Journal of Affective Disorders, 210, 249-257. https://doi.org/10.1016/j.jad.2016.12.019

Simonoff, E., Pickles, A., Charman, T., Chandler, S., Loucas, T., \& Baird, G. (2008). Psychiatric disorders in children with autism spectrum disorders: Prevalence, comorbidity, and associated factors in a population-derived sample. Journal of the American Academy of Child and Adolescent Psychiatry, 47, 921-929. https://doi. org/10.1097/CHI.0b013e318179964f

Sinclair, C., Meredith, P., Strong, J., \& Chalkiadis, G. A. (2019). Sensory modulation: An important piece of the disability puzzle for adolescents with persistent pain. Clinical Journal of Pain, 35, 121132. https://doi.org/10.1097/AJP.0000000000000663

Siper, P. M., Kolevzon, A., Wang, A. T., Buxbaum, J. D., \& Tavassoli, T. (2017). A clinician-administered observation and corresponding caregiver interview capturing DSM-5 sensory reactivity symptoms in children with ASD. Autism Research, 10, 11331140. https://doi.org/10.1002/aur.1750

Skwerer, D. P., Joseph, R. M., Eggleston, B., Meyer, S. R., \& TagerFlusberg, H. (2019). Prevalence and correlates of psychiatric symptoms in minimally verbal children and adolescents with ASD. Frontiers in Psychiatry, 10, 1-11. https://doi.org/10.3389/fpsyt.2019.00043

Song, M. K., Lin, F. C., Ward, S. E., \& Fine, J. P. (2013). Composite variables: When and how. Nursing Research, 62, 45-49. https:// doi.org/10.1097/NNR.0b013e3182741948

Sparrow, S. S., Balla, D. A., \& Cicchetti, D. V. (1984). Vineland adaptive behavior scales. AGS.

Stadnick, N., Chlebowski, C., Baker-Ericzén, M., Dyson, M., Garland, A., \& Brookman-Frazee, L. (2017). Psychiatric comorbidity in autism spectrum disorder: Correspondence between mental health clinician report and structured parent interview. Autism, 21, 841-851. https://doi.org/10.1177/1362361316654083

Stedman, A., Taylor, B., Erard, M., Peura, C., \& Siegel, M. (2019). Are children severely affected by autism Spectrum disorder underrepresented in treatment studies? An analysis of the literature. Journal of Autism and Developmental Disorders, 49, 1378-1390. https://doi. org/10.1007/s10803-018-3844-y 
Stein, L. I., Polido, J. C., \& Cermak, S. A. (2013). Oral care and sensory over-responsivity in children with autism spectrum disorders. Pediatric Dentistry, 35(3), 230-235.

Stein, L. I., Polido, J. C., Mailloux, Z., Coleman, G. G., \& Cermak, S. A. (2011). Oral care and sensory sensitivities in children with autism spectrum disorders. Special Care in Dentistry, 31, 102-110. https://doi.org/10.1111/j.1754-4505.2011.00187.x

Stokes, J., Pogge, D., Wecksell, B., \& Zaccario, M. (2011). Parent-child discrepancies in report of psychopathology: The contributions of response bias and parenting stress. Journal of Personality Assessment, 93, 527-536. https://doi.org/10.1080/00223891.2011.594131

Tager-Flusberg, H., \& Kasari, C. (2013). Minimally verbal school-aged children with autism spectrum disorder: The neglected end of the spectrum. Autism Research, 6, 468-478. https://doi.org/10.1002/ aur. 1329

Tavassoli, T., Bellesheim, K., Siper, P. M., Wang, A. T., Halpern, D., Gorenstein, M., Grodberg, D., Kolevzon, A., \& Buxbaum, J. D. (2016). Measuring sensory reactivity in autism Spectrum disorder: Application and simplification of a clinician-administered sensory observation scale. Journal of Autism and Developmental Disorders, 46(1), 287-293. https://doi.org/10.1007/s10803-015-2578-3

Tavassoli, T., Brandes-Aitken, A., Chu, R., Porter, L., Schoen, S., Miller, L. J., Gerdes, M. R., Owen, J., Mukherjee, P., \& Marco, E. J. (2019). Sensory over-responsivity: Parent report, direct assessment measures, and neural architecture. Molecular Autism, 10, 4. https://doi.org/10.1186/s13229-019-0255-7

Tavassoli, T., Miller, L. J., Schoen, S. A., Jo Brout, J., Sullivan, J., \& Baron-Cohen, S. (2018). Sensory reactivity, empathizing and systemizing in autism spectrum conditions and sensory processing disorder. Developmental Cognitive Neuroscience, 29, 72-77. https:// doi.org/10.1016/j.den.2017.05.005

Taylor, M. J., Gustafsson, P., Larsson, H., Gillberg, C., Lundström, S., \& Lichstenstein, P. (2018). Examining the association between autistic traits and atypical sensory Reactivity: A twin study. Journal of the American Academy of Child and Adolescent Psychiatry, 57(2), 96-102. https://doi.org/10.1016/j.jaac.2017.11.019

Thye, M. D., Bednarz, H. M., Herringshaw, A. J., Sartin, E. B., \& Kana, R. K. (2018). The impact of atypical sensory processing on social impairments in autism spectrum disorder. Developmental Cognitive Neuroscience, 29, 151-167. https://doi.org/10.1016/j.dcn. 2017.04.010

Tomchek, S. D., \& Dunn, W. (2007). Sensory processing in children with and without autism: A comparative study using the short sensory profile. American Journal of Occupational Therapy, 61, 190 200. https://doi.org/10.5014/ajot.61.2.190

Trevisan, D. A., Mehling, W. E., \& McPartland, J. C. (2020). Adaptive and maladaptive bodily awareness: Distinguishing interoceptive sensibility and interoceptive attention from anxiety-induced somatization in autism and alexithymia. Autism Research, 14, 240-247. https://doi.org/10.1002/aur.2458

Tseng, M. H., Fu, C. P., Cermak, S. A., Lu, L., \& Shieh, J. Y. (2011). Emotional and behavioral problems in preschool children with autism: Relationship with sensory processing dysfunction. Research in Autism Spectrum Disorders, 5, 1441-1450. https://doi. org/10.1016/j.rasd.2011.02.004

Volker, M. A., Lopata, C., Smerbeck, A. M., Knoll, V. A., Thomeer, M. L., Toomey, J. A., \& Rodgers, J. D. (2010). BASC-2 PRS profiles for students with high-functioning autism spectrum disorders. Journal of Autism and Developmental Disorders, 40, 188-199. https://doi.org/10.1007/s10803-009-0849-6

Watson, L. R., Patten, E., Baranek, G. T., Poe, M., Boyd, B. A., Freuler, A., \& Lorenzi, J. (2011). Differential associations between sensory response patterns and language, social, and communication measures in children with autism or other developmental disabilities. Journal of Speech, Language, and Hearing Research, 54, 1562-1576. https://doi.org/10.1044/1092-4388(2011/10-0029

Wechsler, D. (2006). Wechsler nonverbal scale of ability: WNV. PsychCorp.

Yeap, S., Kelly, S. P., Sehatpour, P., Magno, E., Garavan, H., Thakore, J. H., \& Foxe, J. J. (2008). Visual sensory processing deficits in schizophrenia and their relationship to disease state. European Archives of Psychiatry and Clinical Neuroscience, 258, 305-316. https://doi.org/10.1007/s00406-008-0802-2

Zachor, D. A., \& Ben-Itzchak, E. (2014). The relationship between clinical presentation and unusual sensory interests in autism spectrum disorders: A preliminary investigation. Journal of Autism and Developmental Disorders, 44, 229-235. https://doi.org/10.1007/ s10803-013-1867-y

Zobel-Lachiusa, J., Andrianopoulos, M. V., Mailloux, Z., \& Cermak, S. A. (2015). Sensory differences and mealtime behavior in children with autism. American Journal of Occupational Therapy, 69, 6905185050p1. https://doi.org/10.5014/ajot.2015.016790

How to cite this article: Rossow T, MacLennan K, Tavassoli $\mathrm{T}$. The relationship between sensory reactivity differences and mental health symptoms in preschool-age autistic children. Autism Research. 2021;1-13. https://doi.org/10.1002/ aur. 2525 